\title{
A OBRA CARTA AO PA/ DE FRANZ KAFKA NA DRAMATURGIA ESSENCIAL DE DENISE STOKLOS*
}

Denise Stoklos, criadora do Teatro Essencial, trouxe ao palco do auditório que tem o seu próprio nome, na Universidade Estadual do Centro oeste, campus de Irati, na data de 09 de outubro de 2013 uma encenação da obra do autor theco Franz Kafka, intitulada Carta ao pai. A narrativa de Kafka, antes de ser uma obra literária é uma carta de cunho pessoal que foi escrita a seu pai, porém nunca entregue. Ela é um desabafo de Franz ao progenitor e, partindo inicialmente da oposição deste ao casamento do filho, abrange toda a vida opressora e angustiante a que o pai o submeteu.

$\mathrm{Na}$ carta notamos como Kafka condena o pai pelo comportamento tirano para com ele, sempre recriminando,
Peça teatral encenada pela atriz Denise Stoklos, na Universidade Estadual do Centro Oeste/UNICENTRO em 09 de outubro de 2013 subjugando, condicionando o filho às suas próprias vontades, sem dar espaço para o crescimento humano, desestimulando, reprimindo, de modo que gerou nele um medo e uma insegurança enorme, que o atormentaram por toda vida. Ao transportar a obra para o palco Stoklos, por meio de seu essencialismo teatral, interpretou de forma brilhante a angústia vivida por Kafka. O cenário simplista, composto apenas por um pequeno divã marca, de certa forma, a solidão e a distância que separava Franz de seu pai Hermann.

O divã tem uma carga semântica muito grande na peça, já que metaforiza o espaço de um consultório psicanalítico, em que o paciente exterioriza suas angústias, medos e opressões. 
1. KAFKA, Carta ao pai, p. 8

2. KAFKA, Carta ao pai, p.11
É o que fez Franz Kafka solitariamente em sua carta dirigida ao progenitor. Não tendo coragem de incutir ao pai diretamente a responsabilidade pelos fracassos e malogros de sua existência, Franz o faz por meio da escrita. Assim, carta e divã se equivalem. Significam uma forma indireta de desabafo, uma "válvula de escape" a um problema que transpassa um incidente momentâneo entre pai e filho, mas é o incisivo martírio imposto gradualmente de um pai a um filho ao longo de praticamente uma vida inteira.

O medo, que desencadeia toda a situação e condição existencial de Franz Kafka, tema central de sua carta ao pai fica evidente nos gestos faciais que Stoklos reproduz ao interpretar o autor theco. Em grande parte da peça a atriz deixou transparecer ao público, por meio dos olhos, ora estalados ora esbugalhados o medo e a apreensão vivificada e descrita por Franz quando estava ao lado do pai. Observamos em Carta ao pai quando o autor se dirige a seu progenitor: "[...] sempre me escondo de você, no meu quarto, com meus livros, com amigos malucos, com ideias extravagantes ${ }^{1}$ [...]." E mais adiante quando ele volta a dizer que " eu era uma

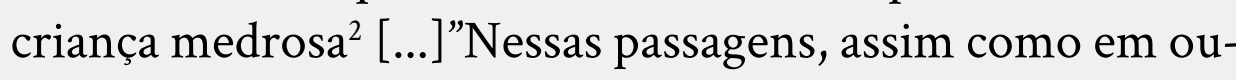
tras, notamos a insegurança do narrador, incrédulo de sua própria existência.

No palco, Denise Stoklos retratou essas passagens andando freneticamente de um lado para outro, mostrando a frágil personalidade de um ser condicionado às vontades do pai, sem muita reação a não ser o medo excessivo que gerava uma pseudo veneração. Os movimentos das mãos da atriz também são extremamente importantes para caracterizar a insegurança e demonstrar o horror e a aversão que o filho, ao longo do tempo, foi nutrindo pelo pai. As mãos cobrindo os olhos e o rosto e deslizando nervosamente pelos cabelos não eram senão a interpretação cênica das lembranças de um discurso sempre inibidor do Kafka pai ao Kafka filho. "Seus recursos oratórios extremamente eficazes e que nunca falhavam, pelo menos comigo, eram: insulto, ameaça, ironia, riso malévolo e - curiosamente - autoacusação ${ }^{3}$."

As mãos dispostas estrategicamente pelo espaço e junto ao corpo, numa articulação dos braços, pernas e dedos representam a já citada insegurança que Franz sentia perante a vida, consequência da tirania de seu pai. Ele afirma isso na carta quando diz: “ [...] perdi a confiança nos meus próprios atos. Tornei-me instável, indeciso [...] me tornei assim só por sua causa ${ }^{4}[\ldots]$ ”. Assim, o não saber onde colocar as mãos na peça teatral, movimentando-as de modo estabanado equivale na narrativa kafkiana a não saber como agir diante das adversidades e situações impostas pela vida. É o corpo cênico trabalhando para descrever as angústias que o filho de Hermann sentia e cujo medo também o impedia de exterioriza-las. Não descritas verbalmente, as angústias de Franz converteram-se consequentemente em sinais
3. KAFKA, Carta ao pai, p. 23

4. KAFKA, Carta ao pai, p.24
EM TESE
BELO HORIZONTE
v. 21
N. 1
JAN.-ABR. 2015
PIMENTEL. A obra Carta ao pai de Franz Kafka na dramaturgia [...] [resenha] . $224-227$ 
corporais evidentes de moléstias, doenças físicas, tremores que culminaram em sua morte prematura.

O tom de voz também marcou a peça do teatro essencial de Denise Stoklos. Na peça em questão, montada, interpretada e dirigida por ela mesma, notamos os momentos em que a personagem se exalta e o tom de voz da atriz eleva-se para demonstrar o sentimento angustiante de se dirigir ao pai, lembrando-o de sua influencia negativa na vida do filho. Em outros momentos há uma fala mais branda, apenas reportando ao pai de como poderia ser a relação entre eles se o autoritarismo patriarcal extremamente avassalador impositivo não predominasse. Em outros ainda, há a interpretação do choro em cena, nos momentos que a angústia da personagem se manifesta de forma mais contundente e transpassa os limites do acanhamento e do medo, chegando ao desespero.

Há momentos ainda, um tanto raros na vida de Franz Kafka, segundo seu relato em Carta ao pai, que ele se sentia satisfeito e até orgulhoso do pai que tinha. Esses momentos circunstanciais se sintetizam quando ele vê o pai chorando um dia por causa do adoecimento da mulher e em outra ocasião em que o pai vai observá-lo pela fresta da porta entreaberta do seu quarto quando ele estava adoentado. Essas situações foram interpretadas no palco apenas com um discreto sorriso, demonstrando certo enternecimento do filho em relação às tímidas e poucas atitudes humanizantes do pai. Cenas esparsas condizentes com os poucos momentos felizes que Kafka supostamente teria ao lado do pai.

O figurino de Stoklos na peça também, assim como a essência de seu teatro, essencial, um vestido longo duma mescla cinza e preto simbolizava também o clima nada satisfatório nem agradável que permeava a atmosfera da escrita da carta ao pai, bem como metaforizava a relação nada amistosa entre eles. Era um clima de embate, de revolta e indignação. Além do que foi falado, notamos a crítica que a atriz faz (pós espetáculo) na peça ao remeter o relacionamento conflituoso dos Kafka ao governo (brasileiro) e o homem brasileiro (o povo). Uma relação opressora também, no qual o primeiro identifica-se com o tirano Hermann Kafka, enquanto que o segundo simboliza o oprimido Franz.

Ela criticou, na oportunidade, também as secretarias de cultura, de todos os níveis de poder executivo do país por oprimir de certa forma a arte teatral, comparando assim tais secretarias ao Kafka pai e o ator teatral ao filho subjugado. Essa foi mais uma peça de Denise Stoklos que certamente ficará na lembrança de quem a assistiu. A atriz transportou ao palco da UNICENTRO e com muito engenho, arte e talento performatizou o essencial da obra do não menos importante Franz Kafka, uma carta que redigiu ao pai. 
5. GIORDANO apud STOKLOS, Carta ao pai: peça teatral da obra de Franz Kafka, s/p
$\mathrm{Na}$ encenação pudemos notar a crise física e mental que o escritor theco dirigiu ao pai em carta. Sozinho deixou de viver o essencial da vida, desfrutar de uma boa relação com os familiares, especialmente com o pai. Sozinha e essencial, também, no palco a atriz Denise Stoklos de forma crítica e direta permitiu refletir um pouco das frágeis relações humanas, convergentes na relação pai/filho, especialmente nos dia atuais, em que notamos as famílias fragmentadas, modelando-se em um novo formato. Para finalizar citemos e reiteremos a importância do ator no Teatro Essencial de Stoklos: "lá, apenas os instrumentos do ator: seu corpo, voz e intuição. Do corpo o espaço, o gesto o movimento. Da voz a palavra, a sonoridade, o canto. Da intuição, o ritmo, a emoção, a dramaturgia ${ }^{5}[\ldots]$ ".

Observando essa consideração da atriz em relação ao seu teatro, podemos inferir porque ela selecionou a carta de Kafka para a encenação. O corpo já debilitado de Kafka, sua voz pesarosa e sua intuição descrente forneceram elementos essenciais para a peça teatral. A atualização da obra percebida nas relações divã (consultório psicanalítico)/ quarto de hospital, além de outros elementos, como a alternância no tom de voz, de acordo com os momentos da narrativa aliadas à movimentos corporais e faciais fizeram a plateia enxergar o próprio Kafka enclausurado em seus conflitos mais agudos. O palco é o lugar do ator, do humano, todo o resto é secundário e complementar. Assim também é na literatura. $\mathrm{O}$ autor cria a personagem que cria a história. O humano sempre está à frente. Assim a releitura de Kafka por Stoklos contempla a singularidade e evidencia esse ser com suas imperfeições intrínsecas, exteriorizadas com seus gestos, palavras e ações.

\section{REFERÊNCIAS}

GIORDANO, Davi. O Teatro Essencial sob uma perspectiva minimalista. Revista Lindes: estudos sociales del arte y la cultura. Buenos Aires (Argentina), nº 15, s/p, julho/2011.

KAFKA, Franz. Carta ao pai. Tradução e posfácio de Modesto Carone. São Paulo: companhia das Letras, 1997.

STOKLOS, Denise. Carta ao pai: peça teatral da obra de Franz Kafka. Exibida no auditório da Universidade Estadual do Centro Oeste/ UNICENTRO, no campus universitário de Irati no dia 09 de outubro de 2013. Irati, 2013.
EM TESE
BELO HORIZONTE
v. 21
N. 1
JAN.-ABR. 2015
PIMENTEL. A obra Carta ao pai de Franz Kafka na dramaturgia [...] [resenha] P. 224-227 